\title{
BIM integration in education: A case study of the construction technology project Bolt Tower Dolni Vitkovice
}

\author{
Vaclav Venkrbec, Lucie Bittnerova \\ Brno University of Technology \\ Faculty of Civil Engineering, Institute of Technology, Mechanization and Construction Management \\ e-mail: venkrbec.v@vutbr.cz
}

\begin{abstract}
Building information modeling (BIM) can support effectiveness during many activities in the AEC industry. even when processing a construction-technological project. This paper presents an approach how to use building information model in higher education, especially during the work on diploma thesis and it supervision. Diploma thesis is project based work, which aims to compile a construction-technological project for a selected construction. The paper describes the use of input data, working with them and compares this process with standard input data such as printed design documentation. The effectiveness of using the building information model as a input data for construction-technological project is described in the conclusion.
\end{abstract}

Key words: building information model, BIM, teaching, construction management, steel structure,

\section{Introduction}

Building information modeling (BIM) is with no doubt widely accepted evolution of the AEC industry which affected sector of investors, developers, architects, designers, contractors, construction managers but also the tutors and education sector. Teaching BIM is a frequent subject of discussions in the context of implementation of BIM methodology into national construction industries and standards of each affected country. Perhaps this is due to the different construction industries in each country, but also to differences in the teaching methods and practices not only of countries but of educational institutions in general. There is such a wide range of combinations of different approaches to the issue of "How to teach BIM". This paper presents approach how to lead master student due to diploma thesis work.

\subsection{BIM and teaching}

Many studies, reviews and surveys according to teaching BIM were presented. Some papers are dedicated to general BIM teaching $[1,2,3]$, where BIM capacity of professors and lecturers were evaluated for BIM teaching and concepts and subjects were applied into teaching. Some papers [4] are more focused to construction management, where BIM oriented 
subjects was implemented into curriculum in 2016. The aim of subject was to learn extracting data from model, 4D and 5D modeling and implementation into construction company for using data in project management. Another paper concluded that BIM-based integrated education platform can help students to formulate an understanding of project lifecycles and will be able to provide a large amount of educational materials based on real-world projects and business situations [5]. Important part of the work of construction-technology manager as well as construction-technology student is to utilize or check cost estimation based on BIM methodology. Unfortunately, data on the effectiveness of BIM's use in construction cost estimating remain scarce [6].

\subsection{Input data}

For the designing construction technological part of the construction process it is advisable to collect as many input data as possible. Traditionally, this means collecting tender documentation, bills of quantities, cost estimates and contract. These documents can be achieved in printed or electronic version and it can be editable or not.

\section{Methods}

The Institute of Technology, Mechanization and Construction Management at Brno University of Technology have accredited Master's study programme with Full-Time mode of study called Construction Technology. Students of the last year prepare a constructiontechnology project as a diploma thesis. Project is based on real data obtained from practice, usually project documentation of the real construction project that is not yet, but can be built.

To use the BIM model, to obtain a model in *.ifc or at least in the *.tbp format is needed. The second mentioned format doesn't allow all information about model to user, but for construction technology project use is this type of information representation sufficient. Figure 1 shows basic construction element information screen in Tekla environment.

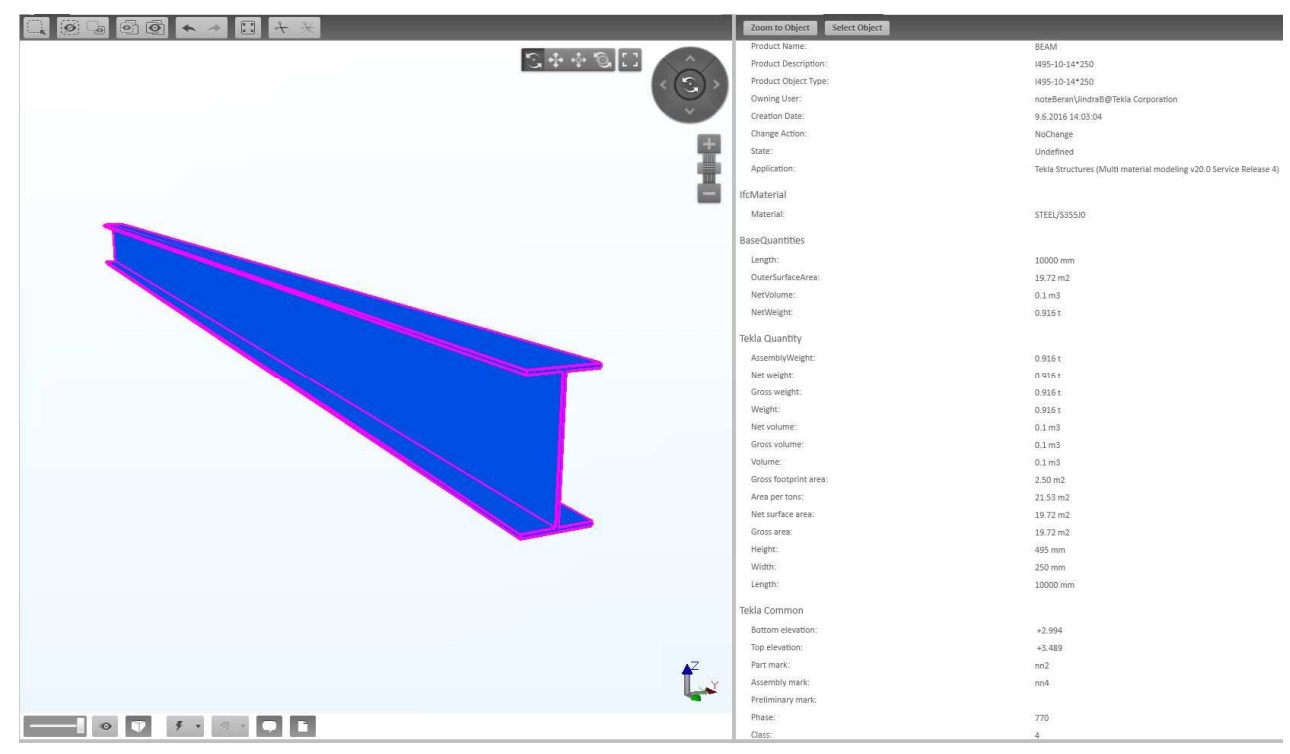

Figure 1: Tekla BIMsight construction element information screen 
It is advisable to parse the model into several parts so that the object model can be divided into individual technological stages. The Tekla BIMsight viewer allows to display and hide individual structure elements by categories. This tool can help to construction-technology engineer with a breakdown according to traditional technological procedures into clearly defined units like a superstructure, loading bearing structures, Non-load-bearing structures etc.

\section{Results - Case study}

In this case study some parts from diploma thesis of the master degree student Lucie Bittnerova are presented.

\subsection{New steel superstructure}

Input data *.tbp model consists of 12 layers due to structure type or by 17 objects. Each object in the model can contain information about the structure element like product description, length, volume, surface area, gross footprint area, or geometrical information like bottom elevation, top elevation.

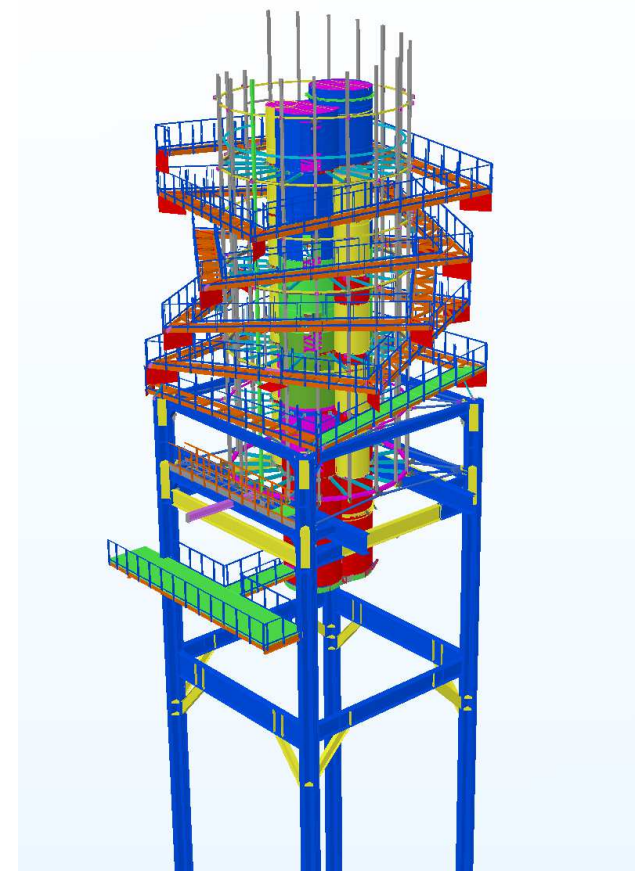

Figure 2: Tekla BIMsight screen of whole construction

The new steel structure of the superstructure is placed on the top of the existing steel structure of the blast furnace No. 1 on the premises of the industrial complex called Dolni Vitkovice in Ostrava city. The so-called Reactivation of Blast Furnaces No. 1 took place on the building. The new superstructure is shaped like a cylinder, which is cladded to create a hexagonal surface. The diameter of the inner cylinder is $9.0 \mathrm{~m}$ and the height is $25.0 \mathrm{~m}$. The wall of the 
cylinder is made up of 19 pillars, which are connected in the individual floors of the superstructure with beams.

Inside the cylinder there is an inner full-length core, which is formed by the projection of three tubes. The two tubes have a diameter of $3.0 \mathrm{~m}$ and the third one has a diameter of $1.5 \mathrm{~m}$. There is another one tube in the interior, but they are not statically affected by the three tubes mentioned above.

Both the outer cylinder and the inner core are independently suspended at the bottom of the M42-S460 inclined drawbar system into the existing blast furnace construction and also into the existing four-framed tower. To ensure the transmission of horizontal forces, there are two levels of horizontal stiffeners in the lower part of the superstructure that connect the superstructure with the furnace structure.

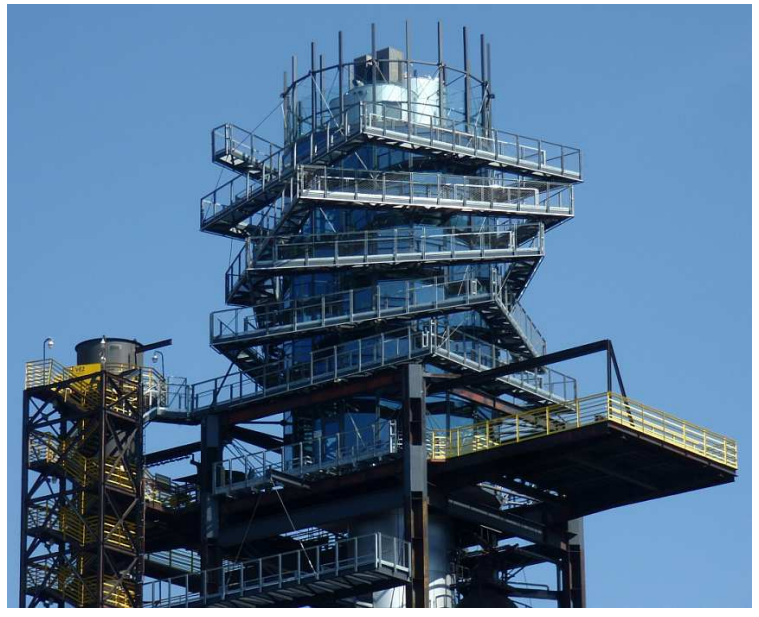

Figure 3: Finished superstructure

\subsection{I. phase - Increasing the stiffness of the existing steel structure}

The BIM model had to be divided into several parts in order to be able to divide the construction into the technological stages. The model viewer allows to user display and hide individual components by category.

First, it was necessary to remove all steel elements from the main cross pillars and then weld the new joints exactly to these points, namely the two-tiered tie structures.

The first level for the joints was at the highest point of the furnace columns for hanging the facade of a new load-bearing structure, and the second level was below the crane track to suspend the bottom of the central tube part.

Subsequently, it was necessary to transport the load-bearing parts weighing up to $350 \mathrm{~kg}$ by means of hand lifting devices up to a height of $60 \mathrm{~m}$, to place them on a column, then to perform geodetic surveys, to evaluate deviations of the placement of the part and finally to perform the final welding of the parts.

Exactly in this way, other joints were assembled. In the course of one month, 20 joints with a total weight of $25.5 \mathrm{t}$ were mounted and subsequently welded. The addition of new beams and 
buckles followed. Using these elements, the 11-meter grid of the main columns was connected and reinforced.

In order to increase the stiffness in the transverse direction, two horizontal "I" beams of 820 $\mathrm{mm}$ are added at $+54.0 \mathrm{~m}$, which will be linked to existing consoles. In order to create an optimally rigid frame, beams of the same dimension will be added at this level even in the longitudinal direction.

The overall stiffness of the furnace will also be increased by adding up to $500 \mathrm{~mm}$ angled struts from welded "I" profiles in all furnace walls at $+45.0 \mathrm{~m}$. Figure 4 shows new stiffening elements by yellow color on the existing furnace.

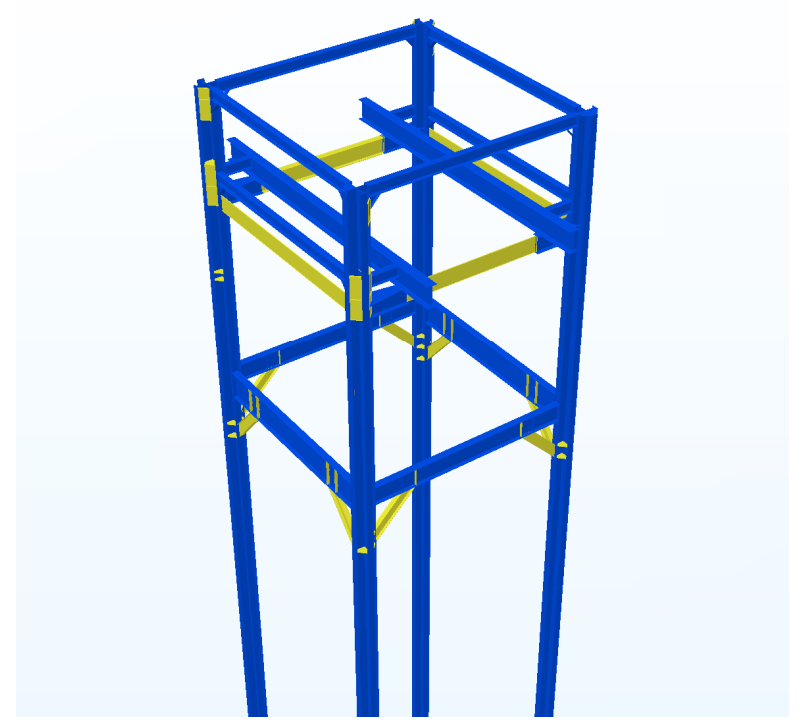

Figure 4: Tekla BIMsight screen of existing construction (blue) with new stiffening elements (yellow)

\subsection{II. phase - Tube suspension, rod activation and assembly of others parts}

In the next phase a model was used for the division of the tubular parts and the generation of assembly units. This has helped to quickly and easily define the weights of individual segment groups. The model was also visually set up so that the assembly could be visualized in steps.

At the ground level, a reinforced surface for pre-assembly of its own steel body was prepared, as well as a surface for the main lifting mechanism - a $140 \mathrm{t}$ track crane. Followed by weighing the individual tubes and in weekly cycles. During the elaboration of the project, it was necessary to eliminate the assembly of the elements in height and also to the accessibility and feasibility of the joints.

All individual parts were gradually assembled at the level of the terrain on the pre-assembly grid of 12 assemblies. Gradually, they were assembled with 2 to 3 pieces approximately $2.5 \mathrm{~m}$ tall, assembled, including a facade horizontal and vertical beams. The entire superstructure was assembled on an assembly platform at its full height. An important structural element of a steel superstructure is that the structure is not built on the furnace but is suspended in the body 
of the supporting steel structure of the blast furnace. The construction of the superstructure is suspended on several rods Macalloy.

After the construction was suspended, it was essential to make important corrections of the forces in the Macalloy rods and also to align the body of the superstructure horizontally and vertically as well as welding the parts together. Then, the two-day cycles followed the assembly of 3 and 4 parts, their mutual welding and completion was done by fitting the upper crown of the facade and the roofs of the main tubes. The total weight of the superstructure is $76.5 \mathrm{t}$.

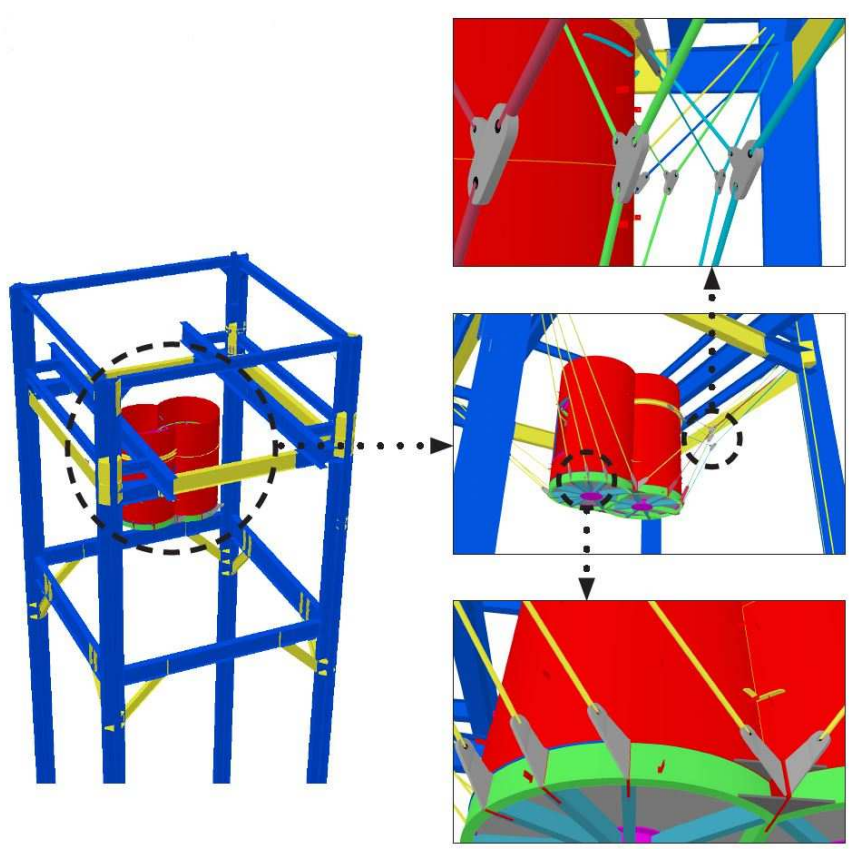

Figure 5: Tekla BIMsight screen of construction of the new tubes and steel pulls

\subsection{III. phase - Installation of the evacuation footbridges}

From standard project documentation, reading such elements that consist of many small elements is the most difficult. In this case study, this is the construction of evacuation bridges with rails. Using the BIM model has helped the student to become more orientated and the possibility of displaying according to the layers has been the basis for a suitable display of the currently executed design.

The footbridges have been assembled from top to bottom, due to the spatial layout of the footbridges in the helix and the need for access for the installers.

The joints were made over a twelve-meter bucket with textile fasteners, which were gradually extended according to the level of the assembled footbridge, while the lever stayed always above the highest footbridge.

These footbridges are not intended for normal traffic for visitors to the tower, but serve only for the evacuation of persons. There are a total of 19 straight arms of width $1.0 \mathrm{~m}$ with and longitudinal slope of about $6 \%$. Both longitudinal bridge beams are located at the middle of the span on the brackets guided by the columns of the outer tube. At the corners, the footbridges are interconnected with the M20 diameter of the S460 steel, the highest level of 
the ropes being pushed from the top of the superstructure where the horizontal stiffener is. The lower footbridges arms are connected to the existing furnace structure by TR $89 \times 6.3$ pipes. The sliding surface is made of anti-slip semi-grids, which are divided into triangular panels because of the geometric shape of the footbridge. The semi-grids are supported around the perimeter by diagonal, transverse cross members and longitudinal beams.

The footbridges will be supplied as a single piece and will be interconnected in the corners by screwing the edges of the marginal U-profiles over the spacers. Each footbridge is a collapsed straight line.

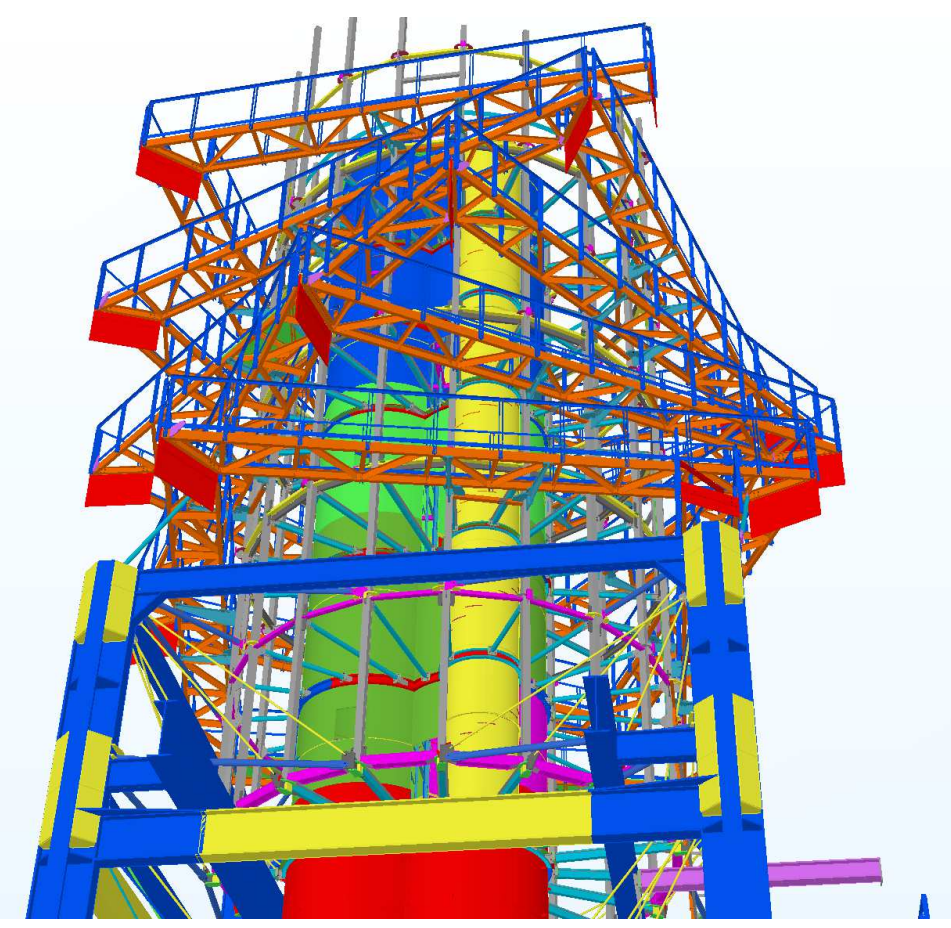

Figure 6: Tekla BIMsight screen of stage III. - suspended footbridges construction

\section{Conclusion}

The paper deals with the implementation of BIM in construction technology management. Specifically, it is the construction of the steel structure of the lookout tower. In order to process the construction technology plan and the choice of suitable construction technologies, it has been shown that the BIM model can help the technology engineer during the phase of designing complex models that contain many small components. It is therefore the use of the geometric model. Preparing to assemble large units requires mass planning for optimal use of lifting mechanisms. A BIM model with a focus on the information part of the model was also used. For each case of the technological stage, it is useful to use another type of BIM model data information portfolio for each specific construction.

The presented study has limitations. The used format does not allow for editing elements, i.e. the model can only be viewed, but the feedback was not used in this case. 
The presented approach has been implemented on specific software. In this case, it is Tekla BIMsight. For other software, the methodology may vary and at present it is not possible to globalize the process, because software varies according to the manufacturer. Space for future research is to find common denominators of several types of commonly available software and to establish a methodology that would be applicable globally.

It can be concluded that the BIM model has improved the efficiency of the student's work and has its place in construction-technology project preparation. It can also help during selecting and optimizing the most appropriate construction mechanisms and technologies for construction.

\section{Acknowledgements}

The outcome has been achieved with the financial support of Standard Internal Grant No. FAST-S-174148 provided by Brno University of Technology. Distributing images and content to third parties is prohibited.

\section{References}

[1] Muller, H., Loures, E., Mendes, R.Jr., Canciglieri, O.Jr., Freitas, M.D.C.D., Frederico, G.F. Developing BIM culture in a university -past and future steps. Advances in Transdisciplinary Engineering, vol. 4, 2016, pp. 358-367.

[2] Puolitaival, T., Forsythe, P. Practical challenges of BIM education. Structural Survey, vol. 34 (45), 2016, pp. 351-366.

[3] Adamu, Z.A., Thorpe, T. How universities are teaching bim: A review and case study from the UK. Journal of Information Technology in Construction, 21, 2016, pp. 119-139.

[4] Matějka, P., Růžička, J., Žák, J., Hájek, P., Tomek, A., Kaiser, J., Veselka, J. The implementation of Building Information Modeling into educational programs at CTU in Prague. CESB 2016 Central Europe Towards Sustainable Building 2016: Innovations for Sustainable Future, 2016, pp. 853-860.

[5] Wang, L., Leite, F. Process-oriented approach of teaching building information modeling in construction management. Journal of Professional Issues in Engineering Education and Practice, 140 (4), 2014, art. no. 04014004.

[6] Nassar, K. Assessing building information modeling estimating techniques using data from the classroom. Journal of Professional Issues in Engineering Education and Practice, 138 (3), 2012 pp. 171-180. 